\title{
Relação entre Divulgação Voluntária de Informações Sociais e \\ Características das Empresas de Capital Aberto
}

\author{
Jéssica Maria da Silva Meireles ${ }^{1}$ \\ Ramon Rodrigues dos Santos ${ }^{2}$ \\ Vera Lúcia Cruz ${ }^{3}$
}

\begin{abstract}
Resumo
Este trabalho verificou a relação entre a divulgação voluntária de informações sociais e as características das empresas brasileiras de capital aberto listadas na BM\&F Bovespa, assumindo-se as hipóteses de que a divulgação voluntária de informações sociais está relacionada positivamente ao tamanho da empresa, sua rentabilidade, endividamento, participação na carteira ISE e liquidez das ações com uma amostra formada por 70 empresas que divulgaram seus relatórios de sustentabilidade no ano de 2012. Para a análise do nível de divulgação voluntária foi utilizada uma métrica desenvolvida a partir dos estudos de Gonçalves (2011) e Rover (2013) e o Qui-quadrado a fim de confirmar a relação entre as características em estudo e a divulgação voluntária das empresas. Após o teste, as variáveis tamanho, rentabilidade, liquidez de mercado e ISE apresentaram relação com o índice de divulgação voluntária, apresentando significância estatística à níveis satisfatórios. Os resultados demonstram que as empresas evidenciam possuir programas de voluntariado, apresentando os resultados sociais alcançados pelos projetos desenvolvidos, mas não as divulgam por projeto ou programa desenvolvido, trazendo uma falta de comprometimento na continuidade, ou falta de interesse em desenvolver e especificar outros potenciais projetos.
\end{abstract}

Palavras-chave: Divulgação Voluntária; Informações sociais; Legitimidade.

\section{Relation between Voluntary Disclosure of Social Information and Characteristics of Open Capital Companies}

\begin{abstract}
This study investigated the relationship between the voluntary disclosure of social information and characteristics of Brazilian public companies listed on the BM \& F Bovespa, assuming the hypothesis that voluntary disclosure of social information is positively related to firm size, profitability, indebtedness, participation in the ISE portfolio and liquidity of the shares with a sample made up of 70 companies that disclosed their sustainability reports in 2012 . For the analysis of voluntary disclosure level we used a metric developed from studies Gonçalves

1

Graduada em Ciências Contábeis pela Universidade Federal da Paraíba. E-mail: jessicaameireles@hotmail.com. Lattes: http://lattes.cnpq.br/0987318534896595.

${ }^{2}$ Doutorando em Administração pela Universidade Federal de Pernambuco. Mestre em Administração pela Universidade Federal da Paraíba. Graduado em Administração pelo Centro Universitário Cidade Verde. Graduado em Ciências Contábeis pelo Centro Universitário de João Pessoa. Professor da Universidade Federal de Pernambuco (UFPE). E-mail: ramonrdgs@gmail.com. Lattes: http://lattes.cnpq.br/5491929027285609.

${ }^{3}$ Doutoranda em Administração pela Universidade Potiguar. Mestre em Ciências Contábeis pela Universidade Federal de Pernambuco. Professora da Universidade Federal da Paraíba. E-mail: veralc22@,hotmail.com. Lattes: http://lattes.cnpq.br/4026224716762007.
\end{abstract}


(2011) Rover (2013) and Qui-square in order to confirm the relationship between the characteristics of the study and voluntary disclosure of the companies. After testing, the size variables, profitability, market liquidity and ISE had relationship with the voluntary disclosure index, statistical significance at satisfactory levels. The results show evidence queas companies have volunteer programs, with the social achievements of developed projects, but does not disclose per project or program, bringing a lack of commitment to continuity, or lack of interest to develop and specify other potential projects.

Keywords: Voluntary Disclosure; Social Information; Legitimacy. 


\section{Relação entre Divulgação Voluntária de Informações Sociais e Características das Empresas de Capital Aberto}

\section{Introdução}

A divulgação de informações voluntárias por parte das organizações representa um instrumento para que as mesmas se diferenciem das demais, relativamente à maneira que demonstram seu desempenho, estratégias e diferenciais competitivos. Dias Filho (2007) comenta que se tem observado notável crescimento no volume de evidenciações corporativas de caráter voluntário, em que peculiarmente privilegiam questões de natureza social.

A inclinação das empresas para a noção de desenvolvimento baseada na ideia de desenvolvimento sustentável tem levado a uma crescente demanda por divulgação social e ambiental, em que está diretamente relacionada à política de Responsabilidade Social Corporativa (RSC) das entidades. A RSC pode ser definida como a forma de gestão a qual apresenta como uma de suas finalidades a integração entre os desempenhos econômicos, sociais e ambientais - o Triple Bottom Line da sustentabilidade empresarial (VELLANI, 2011).

Consoante Machado, Machado e Murcia (2011), as empresas adotam certos procedimentos a fim de atingir a legitimidade social e por pressões decorrentes da própria sociedade. Neste contexto, existem estudos que comprovam que as empresas divulgam informações voluntárias a fim de atender as pressões sociais, melhorar sua imagem, ou seja, legitimar-se em seu meio, gerenciar stakeholders específicos, atrair fundos de investimentos, ganharem determinados prêmios de divulgação e cumprir determinações referentes à sua atividade econômica (BURGWAL; VIEIRA, 2014), sendo também estimuladas pelas características das organizações - sua rentabilidade, participação no mercado, tamanho e endividamento.

O presente trabalho tem por proposta verificar a existência de associação entre a divulgação voluntária das práticas sociais e as características das empresas de capital aberto listadas na antes BM\&FBovespa, atual B3 (Brasil, Bolsa, Balcão) buscando analisar se determinadas peculiaridades das mesmas influenciam na divulgação da informação. A evidenciação social tem por finalidade ser utilizada como um meio de comunicação entre a organização e a sociedade, divulgando seus empreendimentos socialmente responsáveis, sendo suas ações apresentadas em relatórios sociais e servindo como instrumento para beneficiar a imagem organizacional (GONÇALVES, 2013).

Por conseguinte, o disclosure de informações de caráter social apresenta-se como uma mais nova responsabilidade da ciência contábil, uma vez que as empresas buscam atender as exigências da sociedade, ciente de que irão alcançar a lucratividade, comportando-se de forma socialmente 
responsável e disponibilizando informações de natureza financeira e econômica relacionadas às suas ações sociais aos seus stakeholders, transmitindo-os tais valores.

Neste contexto, o presente estudo tem a seguinte questão de pesquisa: Existe relação entre a divulgação voluntária de informações sociais e as características das empresas de capital aberto?

A importância do disclosure social vem crescendo entre as organizações, uma vez que as mesmas estão conferindo maior atenção às questões sociais e acabam por evidenciar cada vez mais suas práticas relativas a este tema. Dessa forma, este trabalho justifica-se pelo fato de que estudar o que estimula as organizações a divulgarem suas ações sociais confere à contabilidade a responsabilidade de reportar informações, não apenas financeiras e econômicas, mas de natureza social - objetivando predizer e explicar através do estudo das características das organizações, representadas neste trabalho - o tamanho da empresa, a rentabilidade, a participação no ISE, liquidez de mercado, o endividamento - identificando por meio das mesmas, o que motiva as empresas a divulgarem informações não obrigatórias de natureza social.

\section{Revisão Bibliográfica}

\subsection{Teoria da Legitimidade}

A teoria da legitimação está associada a um contrato social imaginário em que os integrantes da sociedade, possuidores de direitos e obrigações, devem exercê-los objetivando equilíbrio entre os mesmos. Logo, quando uma organização não cumpre ao contrato, procedendo perante os integrantes de forma insatisfatória, ela rompe com o contrato estabelecido e a sociedade vem a impedir a continuidade das operações da empresa (MACHADO; MACHADO; MURCIA, 2011).

Assim, as organizações desejam manter em equilíbrio seus valores organizacionais e os sociais, para não apresentar uma lacuna de legitimidade, ou seja, rompimento do contrato social (BURGWAL; VIEIRA, 2014). As empresas se desempenharão da melhor maneira para ressarcir ou compensar o contrato social rompido.

Neste contexto, a teoria da legitimidade possivelmente é a teoria mais amplamente utilizada para explicar a divulgação de informações sociais e ambientais por parte das empresas. As pressões sociais em busca de uma responsabilidade sustentável pelas organizações fazem com que a mesma anseie atender tais exigências a fim de manter-se em continuidade, incorporando ações socioambientais em seu planejamento estratégico.

\subsection{Teoria da Divulgação Voluntária}

A divulgação voluntária de informações é uma linha de pesquisa que possui por finalidade elucidar o fenômeno da divulgação, a qual é advinda da teoria da divulgação (CUNHA; RIBEIRO, 
2008). De acordo com Salotti e Yamamoto (2005), a teoria da divulgação pode ser baseada em associação, eficiência ou julgamento. A divulgação baseada em associação analisa os efeitos da divulgação e as modificações sobre as ações dos indivíduos enquanto agentes investidores no momento da divulgação. Por conseguinte, a divulgação baseada em eficiência investiga quais são as formas preferidas de divulgação na ausência de conhecimento prévio da informação (RUFINO; MONTE, 2014).

Quando se reporta a divulgação de informações sociais, esta teoria busca explicar os efeitos de determinadas variáveis na divulgação de informação social executada. Entende-se por divulgação social segundo Burgwal e Vieira (2014) a apresentação de informações públicas ou privadas, financeiras ou não, quantitativas ou qualitativas referente ao gerenciamento das questões sociais das empresas. Assim, como a divulgação de tais informações é ausente de regulamentação, torna-se importante buscar compreender quais fatores internos vem a estimular os gestores a divulgarem as informações.

Esta teoria quando discorre sobre a divulgação de informação de caráter social é complementada por outras as quais buscam explicar o porquê das empresas estarem de forma crescente apresentando informações sobre sua gestão social.

\subsection{Evidenciação de Informações Sociais}

A evidenciação é um meio através do qual a ciência contábil demonstra sua utilidade e objetivos, especificando-se, como um instrumento pelo qual ela deve cumprir suas finalidades, ou seja, comunicando aos seus usuários informações relevantes para orientar a tomada de decisão (DIAS FILHO, 2007).

As organizações divulgam informações objetivando promover a necessidade dos diversos tipos de usuários, podendo fazê-la de forma obrigatória ou voluntária. Neste contexto, Moraes (2014) destaca que a divulgação obrigatória é caracterizada pela existência de regulamentação, realizada de maneira impositiva, enquanto que a divulgação voluntária refere-se a informações complementares, disponibilizadas de acordo com as peculiaridades e decisão das empresas.

Com isso, a divulgação de informações sociais pelas organizações representa utilidade tanto para o público quanto também para a empresa, acabando por favorecer uma relação mais íntima com seus usuários, melhorando sua imagem e proporcionando autoavaliação pelos gestores.

\subsection{Estudos Anteriores}

O estudo de Dias Filho (2007) teve como objetivo buscar evidências do poder preditivo e explicativo da teoria da legitimidade relativamente à política de evidenciação de conteúdo social e 
ambiental. O estudo apontou o fato de que as empresas utilizam a ciência contábil não apenas como meio de apoio a decisões de caráter econômico, mas também como instrumento para adquirir, manter e recuperar legitimidade no ambiente onde estão inseridas.

Gonçalves, Pirani e Borger (2007) estudaram a abrangência e forma de evidenciação da responsabilidade social por bancos privados cujas ações estão listadas no Índice de Sustentabilidade Empresarial (ISE) - e verificaram que, embora igualmente reconhecidos como socialmente responsáveis, conforme os critérios que os compõem no ISE, existem diferenças na qualidade de evidenciação destas instituições financeiras.

Milani Filho (2008) investigou se as empresas que se declaram socialmente responsáveis divulgam informações financeiras específicas sobre os recursos gastos em benefício público (investimento social privado) e também, verificar a significância da dimensão desses gastos entre empresas cujos produtos estão associados às externalidades negativas $\mathrm{e}$ as organizações participantes do Índice de Sustentabilidade Empresarial (ISE). Os resultados demonstraram que nem todas as organizações que declaram realizar investimentos sociais evidenciam o mesmo, não divulgam informações financeiras sobre o valor de gastos sociais e acabam gerando dúvidas sobre a efetividade dos investimentos desenvolvidos para a comunidade.

Cunha e Ribeiro (2008) investigaram quais os incentivos das companhias negociadas no mercado acionário brasileiro para divulgar voluntariamente informações de natureza social. Os referidos autores concluíram que a divulgação de tais informações está relacionada positivamente ao nível de governança corporativa, ao desempenho, ao tamanho e a divulgação em períodos anteriores.

Macagnam (2009) buscou identificar os fatores que influenciam a extensão da evidenciação de informações voluntárias sobre recursos intangíveis, de empresas listadas no mercado de capitais espanhol. Os resultados demonstraram que fatores como o tamanho, setor, endividamento, grau de internacionalização, anos de existência e a diferença entre o preço da ação sobre o valor contábil da empresa explicaram a maior extensão de evidenciação dos recursos intangíveis. Entretanto, fatores como a rentabilidade, grau de monopólio e o capital flutuante da organização explicam a menor extensão da evidenciação de tais informações.

Gonçalves et al. (2013) analisaram a relação entre o nível de social disclosure e o custo de capital próprio em companhias abertas brasileiras. Os resultados indicaram que há relação negativa entre o custo de capital próprio e o nível de social disclosure, informando para o mercado de ações brasileiro uma nítida relevância de eficiência de mercado. 


\section{Metodologia}

Para constituir a amostra foram selecionadas 70 empresas com ações mais negociadas em 2012 pertencentes a diferentes setores de atividades, listadas na BM\&FBovespa e seus respectivos relatórios anuais ou de sustentabilidade. Foram utilizados o portal eletrônico da BM\&FBovespa e o banco de dados Economática ${ }^{\circledR}$, para a obtenção dos dados primários, referentes às características das empresas.

\subsection{Métrica para Análise das Informações Sociais}

Moraes (2014) discorre que quando o pesquisador define o foco para a análise da divulgação social objeto da sua pesquisa, ele busca construir uma métrica que tende a ser específica e em conformidade com o contexto desenvolvido pelo trabalho. Desta forma, a métrica para análise da divulgação social desta pesquisa foi construída a partir de estudos anteriores de Gonçalves (2011) e Rover (2013), obtendo-se o Índice de Divulgação Voluntária (IDV).

Gonçalves (2011) elaborou o Índice de Social Disclosure, tomando por base sete estudos e, utilizando como instrumento de pesquisa três dimensões: a dimensão de avaliação da informação, dimensão de mensuração e dimensão de padrão de relatórios, buscando apresentar as características dos itens ora evidenciados, tanto de forma quantitativa, quanto de forma qualitativa. Assim, o índice de social disclosure foi elaborado a partir destas dimensões.

No estudo de Rover (2013), o qual também foi utilizado para a elaboração da métrica do presente trabalho, foi utilizada uma métrica de disclosure voluntário socioambiental formado a partir de 20 pesquisas, empreendido entre 1992 e 2011. A autora argumentou que a intenção de se utilizar pesquisas realizadas anteriormente, para elaboração da métrica de disclosure voluntário, é reduzir a subjetividade na seleção das categorias e subcategorias sociais e ambientais, assim o seu modelo de métrica utiliza-se de 80 subcategorias formada por 40 subcategorias relacionadas à divulgação social e 40 subcategorias referentes às informações ambientais.

Moraes (2014) comenta que existe certa dificuldade em mensurar a divulgação voluntária social, pois como se caracteriza de um conceito abstrato, não podendo ser mensurado de forma direta, e que na maioria das vezes, a evidenciação é realizada de forma qualitativa, torna-se complexo conseguir apreender o que se pretende. Uma vez que a métrica é influenciada pelos objetivos da pesquisa - tendo este trabalho o objetivo de primeiramente analisar a informação social e categorizá-la - foram adotados os critérios que utilizam os itens avaliados por Gonçalves (2011) e Rover (2013), uma vez que não há ainda uma definição ou consenso sobre os itens que devem ser analisados na construção de um índice de divulgação voluntária. 
O estudo foi desenvolvido a partir da categorização, e as categorias foram divididas em subcategorias a fim de melhor desenvolver o processo de averiguar as informações. A análise e categorização foram realizadas utilizando uma escala numérica, sem atribuição de pesos para os itens de avaliação, evidenciando as variações na qualidade da informação. Seguindo o estudo de Gonçalves (2011), o estudo adotou uma escala ordinal de quatro pontos objetivando categorizar a informação acentuando sua qualidade.

Para a aplicação da escala ordinal procedeu-se à elaboração de itens que fornecesse evidências suficientes acerca da evidenciação e prestação de contas das ações sociais de caráter voluntário pelas empresas, apresentadas no Quadro 1, sintetizando a construção do índice de evidenciação social. Os itens foram elaborados a partir das pesquisas de Gonçalves (2011) e Rover (2013) e o instrumento de pesquisa foi construído com a finalidade de capturar apenas as informações sociais de caráter voluntário, sendo desconsideradas aquelas de natureza obrigatória.

Quadro 1: Métrica para análise da categoria das Informações Sociais

\begin{tabular}{|c|l|c|}
\hline Ordem & \multicolumn{1}{|c|}{ Item a ser avaliado } & Estudo anterior \\
\hline 1 & Descrição dos programas de voluntariado & Rover (2013) \\
\hline 2 & Descrição de programas sociais futuros e em andamento & Gonçalves (2011) \\
\hline 3 & Descrição dos objetivos e metas para os programas sociais & Gonçalves (2011) \\
\hline 4 & Relação dos programas sociais com os valores da empresa & Gonçalves (2011) \\
\hline 5 & Avaliação das necessidades locais para realização dos programas sociais & Gonçalves (2011) \\
\hline 6 & $\begin{array}{l}\text { Descrição de aspectos para melhoria dos resultados sociais obtidos nos } \\
\text { programas sociais }\end{array}$ & Gonçalves (2011) \\
\hline 7 & Resultados sociais obtidos nos programas sociais & Gonçalves (2011) \\
\hline 8 & Frequência da divulgação dos relatórios de responsabilidade social & Gonçalves (2011) \\
\hline 9 & $\begin{array}{l}\text { Projeção do fluxo de caixa futuro da alocação de recursos em programas } \\
\text { sociais }\end{array}$ & Gonçalves (2011) \\
\hline 10 & $\begin{array}{l}\text { Valor econômico e/ou financeiro dos recursos humanos envolvidos em } \\
\text { programas de voluntariado }\end{array}$ & Gonçalves (2011) \\
\hline 11 & $\begin{array}{l}\text { Valor econômico e/ou financeiro dos recursos materiais destinados aos } \\
\text { programas sociais }\end{array}$ & Rover (2013) \\
\hline 12 & Doações de recursos para entidades de utilidade pública ou OSCIP & \\
\hline
\end{tabular}

Fonte: Adaptado de Gonçalves (2011) e Rover (2013)

Elaborado o instrumento de coleta de dados, segue-se a elaboração da categorização teórica dos itens para avaliação da qualidade da informação, utilizando-se dos mesmos critérios que Gonçalves (2011), descritos no Quadro 2. 
Quadro 2: Categorias teóricas para avaliação da evidenciação da informação social

\begin{tabular}{|c|l|}
\hline Categoria & \multicolumn{1}{c|}{ Critério de Classificação } \\
\hline Restrito & Se a empresa não divulga a informação avaliado pelo item ora proposto. \\
\hline Baixo & $\begin{array}{l}\text { Se a empresa divulga a informação avaliada pelo item proposto, contudo, não o faz por programa } \\
\text { social ou área de atuação, ou seja, a informação é divulgada de modo geral com uso de expressões } \\
\text { como: "os programas sociais", "as ações sociais", entre outros. }\end{array}$ \\
\hline Médio & $\begin{array}{l}\text { Se a empresa divulga a informação avaliada pelo item proposto, fazendo-o por área de atuação, ou } \\
\text { de alguns programas sociais. }\end{array}$ \\
\hline Amplo & $\begin{array}{l}\text { Se a empresa divulga a informação avaliada pelo item proposto de maneira analítica, ou seja, há } \\
\text { informação por programa social. A característica dessa informação é de maior precisão e } \\
\text { amplitude, como por exemplo, "o projeto A...". }\end{array}$ \\
\hline
\end{tabular}

Fonte: Adaptado de Gonçalves (2011)

Para a avaliação quantitativa, foi utilizada uma escala de quatro pontos, objetivando quantificar as categorias teóricas, permitindo dessa forma, a obtenção do índice de divulgação e análises estatísticas, em que a categoria Restrito recebeu o valor de 1 (um), a categoria Baixo o valor 2 (dois), a categoria Médio o valor 3 (três) e a categoria Amplo o valor 4 (quatro).

\subsection{Hipóteses de Pesquisa}

Quando a informação a ser divulgada é voluntária e de natureza social, Cunha e Ribeiro (2008) comentam que a decisão de divulgar ou não tais informações, são endógenas e explicadas por características da própria organização, como o desempenho, práticas de governança corporativa, tamanho, endividamento, ressaltando a relação positiva entre a divulgação voluntária de informações e as características das empresas.

Neste contexto, este trabalho busca investigar se determinadas características das empresas como seu tamanho, rentabilidade, participação no ISE, endividamento e liquidez de mercado influenciam positivamente na divulgação voluntária de informações acerca das práticas sociais das companhias. Diante disto, têm-se as seguintes hipóteses de pesquisa:

\section{H1:O nível de divulgação de informações voluntárias de natureza social está associado} positivamente ao tamanho da empresa.

Conforme Burgwal e Vieira (2014), estudos empíricos constataram relações significativas entre o nível de divulgação social e o tamanho da empresa. Corroborando, esta relação positiva entre o tamanho da empresa e o nível de divulgação corresponde ao fato que, organizações de grande porte estão operando mais intensamente nos negócios e em maior escala, gerando influência sobre a sociedade onde estão inseridas, buscando atender as necessidades de muitos stakeholders, os quais demonstram interesse ou potencial interesse por questões sociais e ambientais. 
Por estarem em maior evidência devido ao seu tamanho, as empresas desejam reduzir seu custo de capital e atender a stakeholders específicos, melhorando assim, seu desempenho (MAPURUNGA et al., 2011). Uma das formas encontradas pelas empresas para alcançarem tais finalidades é a divulgação voluntária de informações.

H2: O nível de divulgação de informações voluntárias de natureza social está associado positivamente à rentabilidade.

Segundo Macagnan (2009), a rentabilidade é considerada variável explicativa da extensão de informação evidenciada pela organização. Com isso, organizações mais rentáveis tendem a evidenciar mais informações buscando se diferenciar das menos rentáveis, diminuindo o risco de seleção adversa (MURCIA; SANTOS, 2009).

H3: O nível de divulgação de informações voluntárias de natureza social está associado positivamente à liquidez das ações da empresa.

Moraes (2014) destaca que os mercados financeiros buscam informações de alta qualidade baseadas em evidenciações com elevada transparência e completas, aumentando a confiança do usuário, afetando positivamente na liquidez das ações. Quando se referem à evidenciação de informações sociais, o autor comenta que quando ocorre maior evidenciação de tais informações, um dos benefícios que merecem destaque é o aumento de liquidez de mercado.

H4: O nível de divulgação de informações sociais está associado positivamente a participação no Índice de Sustentabilidade Empresarial.

Teixeira, Nossa e Funchal (2011) comentam que o Índice Bovespa de Sustentabilidade Empresarial (ISE) foi criado objetivando atender a crescente demanda por investimentos socialmente responsáveis. Em 2005, o ISE foi criado em conjunto com outras instituições com a finalidade de ser um instrumento para análise comparativa do desempenho das empresas listadas sob o aspecto da sustentabilidade corporativa, abarcando as dimensões econômica, social e ambiental (BM\&FBOVESPA, 2014). As empresas participantes do ISE, através dos requisitos exigidos para fazerem parte do mesmo, tendem a exercer em maior escala, práticas de ações sociais. Assim, acabam por divulgá-las.

H5: o nível de divulgação de informações voluntárias de natureza social está associado positivamente ao endividamento. 
Murcia e Santos (2009) verificaram que empresas com endividamento elevado possuem maior nível de disclosure voluntário que empresas de menor grau de endividamento. Devido ao seu endividamento, elas tendem a divulgar voluntariamente mais informações a fim de satisfazer seus credores, uma vez que estão sendo controladas de forma mais intensa por instituições financeiras do que as de menor endividamento - decorrendo assim, a uma maior divulgação.

\section{Análise dos Resultados}

\subsection{Análise Descritiva da Divulgação Voluntária de Informação Social}

A amostra em estudo é formada por 70 (setenta) empresas analisadas no período de 2012. Ressalta-se que não foram consideradas, para efeito de análise, as informações divulgadas nos portais eletrônicos ou sites das empresas em estudo. Primeiramente, foi realizada uma análise de conteúdo, considerando relatórios de sustentabilidade das empresas presentes na amostra, os quais serviram de suporte para a coleta de dados referente à divulgação voluntária de informações sociais.

Para demonstrar os resultados referentes aos níveis de divulgação voluntária pelas empresas, foi utilizada a moda como técnica estatística descritiva. O resultado evidenciado quanto à moda, mostra os valores mais recorrentes em relação ao número de observações. Após o resultado da moda dos itens avaliados, iniciou-se a atribuição às classificações em: "Restrito" equivalendo a pontuação 1; "Baixo", 2; "Médio", 3 e "Amplo", 4. Abaixo, os resultados médios da análise da evidenciação de informações divulgados nos relatórios por item.

Tabela 1: Nível Médio de Divulgação da Evidenciação Social por Item

\begin{tabular}{lc}
\hline \multicolumn{1}{c}{ Item Avaliado } & Resultado \\
\hline Descrição dos programas de voluntariado & Amplo \\
Descrição dos programas sociais futuros e em andamento & Restrito \\
Descrição dos objetivos e metas para os programas sociais & Médio \\
Relação dos programas sociais com os valores da empresa & Baixo \\
Avaliação das necessidades locais para realização dos programas sociais & Restrito \\
Descrição de aspectos para melhoria dos resultados sociais obtidos nos programas sociais & Restrito \\
Resultados sociais obtidos nos programas sociais & Amplo \\
Frequência da divulgação dos relatórios de responsabilidade social & Baixo \\
Projeção do fluxo de caixa futuro da alocação de recursos em programas sociais & Restrito \\
Valor econômico e/ou financeiro dos recursos humanos envolvidos em programas de voluntariado & $\underline{\text { Restrito }}$ \\
Valor econômico e/ou financeiro dos recursos materiais destinados aos programas sociais & Restrito \\
Doações de recursos para entidades de utilidade pública ou OSCIP & $\underline{\text { Restrito }}$ \\
\hline
\end{tabular}

Fonte: Dados da pesquisa (2018)

A descrição dos programas de voluntariado possui por finalidade avaliar a descrição das ações sociais de programas de voluntariado das empresas - por sua vez, a categoria "amplo" demonstra que as empresas apresentam tendência para a divulgação desta informação. Este 
resultado denota que as organizações estão possivelmente apoiando e incentivando programas de voluntariado e evidenciando-os em seus relatórios como ações desenvolvidas pelas mesmas.

No que se refere à descrição dos programas sociais futuros e em andamento, o qual possui a finalidade de identificar as ações que são desenvolvidas pelas organizações, nota-se a não divulgação da informação sobre os projetos sociais em andamento e futuros. $\mathrm{O}$ fato de a empresa decidir não divulgar esta informação demonstra a provável falta de comprometimento da empresa com a continuidade das ações sociais, podendo trazer insegurança para aqueles que se beneficiam dos programas sociais.

A descrição dos objetivos e metas para os programas sociais apresentam uma divulgação média. A evidenciação desta informação demonstra o comprometimento da empresa, em tornar público a confrontação com o que foi planejado e os resultados. O item relação dos programas sociais com os valores da empresa convergiu a uma divulgação social baixa - a empresa evidenciou a relação, mas não explicou como os seus valores organizacionais influenciaram na proposição dos programas sociais; além disso, apresenta o interesse da empresa na prestação de contas com a intenção de reduzir o impacto negativo de suas atividades. Desta forma, a companhia retrata aquilo que ela acredita e o que almeja na execução dos projetos sociais junto à comunidade.

A avaliação das necessidades locais para realização dos programas sociais apresentou uma divulgação da evidenciação social restrita - ressalta-se que o objetivo deste item é analisar se a empresa realiza avaliação das necessidades locais e como esta avaliação influencia na proposição e/ou implantação dos programas sociais, atendendo ou não a demandada comunidade. Assim, a análise feita, demonstra que as empresas decidem não divulgar essa informação, ou não fazem essa avaliação, levando o usuário a perceber que não existe relação entre a implantação do programa social e a identificação das necessidades da comunidade, refletindo que as demandas da mesma não são supridas.

O item descrição de aspectos para melhoria dos resultados sociais obtidos nos programas sociais possui como objetivo evidenciar a necessidade de melhorias na realização dos programas sociais, a avaliação dos programas e como as melhorias devem ser implementadas nos mesmos; observando as metas que foram definidas, apresentou neste estudo uma divulgação restrita. Observa-se que as maiorias das empresas analisadas não evidenciaram informações relativas à preocupação em revisar seus objetivos, metas e avaliação dos seus programas.

O propósito do item resultados sociais obtidos nos programas sociais reside em averiguar os resultados por meio da atuação da empresa junto à comunidade, e convergiu à divulgação social ampla - os resultados obtidos são evidenciados e divulgados voluntariamente por programa social. Gonçalves et al. (2013) elucidam que tendência para a evidenciação e a divulgação desta 
informação é ampla e esperada, uma vez que a divulgação dos resultados dos projetos sociais desenvolvidos pelas empresas implica no aumento de pontos positivos para a imagem da empresa frente aos stakeholders e comunidade local.

A frequência de divulgação dos relatórios de responsabilidade social tem por finalidade analisar se as empresas informam aos usuários a tempestividade de suas divulgações (MORAES, 2014) demonstrando que a divulgação tende para uma evidenciação baixa. Quando a empresa disponibiliza a divulgação um calendário ou de determinadas datas, constata compromisso com seus usuários em prestar contas de suas atividades - assentando um compromisso com os mesmos.

Referente à projeção do fluxo de caixa da alocação de recursos em programas sociais, objetivou-se averiguar se os recursos financeiros a serem alocados em programas sociais são evidenciados. Tal item analisado apresentou divulgação social restrita, apontando por parte das empresas a decisão da não divulgação dos fluxos de caixa alocados para projetos desenvolvidos pelas mesmas. Observa-se que a não divulgação desta informação acarreta - de certa forma, indeterminação quanto à continuidade das ações sociais desenvolvidas pelas companhias e o não compromisso com o planejamento e financiamento dos programas sociais, impossibilitando a projeção, em longo prazo, das ações sociais realizadas.

A divulgação do valor econômico e/ou financeiro dos recursos humanos envolvidos em programas de voluntariado buscou identificar gastos designados aos programas de voluntariado - ao qual neste estudo apresentou divulgação restrita. Tais gastos reportam-se as horas despendidas aos programas de voluntariado (MORAES, 2014), cabendo destacar que tal item também evidencia se a empresa possui programa de voluntariado. Tal item é corroborado ao valor econômico e /ou financeiro dos recursos materiais destinados aos programas sociais - que objetiva evidenciar a destinação de recursos materiais, ou os gastos realizados através de doações. Muitas empresas revelam que destinam recursos materiais aos projetos, mas não divulgam se ocasionou custo para a organização.

O último item buscou identificar se as empresas analisadas divulgam os gastos relativos a doações de recursos para entidades de utilidade pública, organizações não governamentais (ONGs) e sociedades civis de interesse público, apresentando divulgação voluntária restrita - revelando que as empresas decidem em não divulgar quanto de recursos econômicos são transferidos para estas organizações ou se as mesmas destinam recursos para tais organizações.

A seguir, foram elaboradas classificações com as empresas as quais apresentaram maiores e menores níveis de divulgação voluntária social, conforme a métrica utilizada. Por conseguinte, a posição das organizações foi baseada no índice médio obtido pelas empresas referente ao ano de 2012. Percebe-se a priori que as atividades que mais impactam o meio ambiente, ou que 
influenciam no funcionamento socioeconômico, são formadas pelas organizações que mais prestam contas voluntariamente dos seus projetos sociais desenvolvidos. As empresas com menores níveis de divulgação voluntária social pertencem ao setor de comércio.

Tabela 2: Classificação das Empresas com Maiores Níveis de Divulgação Voluntária Social

\begin{tabular}{cllc}
\hline Ordem & \multicolumn{1}{c}{ Empresa } & \multicolumn{1}{c}{ Setor/Segmento } & Divulgação (média/em \%) \\
\hline 1 & Tractebel & Energia Elétrica & 96 \\
2 & Natura & Comércio & 92 \\
3 & ItauUnibanco & Finanças e Seguros & 85 \\
4 & Brasil & Finanças e Seguros & 83 \\
5 & Bradesco & Finanças e Seguros & 81 \\
6 & Telef Brasil & Telecomunicações & 79 \\
7 & Eletropaulo & Energia Elétrica & 79 \\
8 & Petrobras & Petróleo e Gás & 77 \\
9 & Suzano & Papel e Celulose & 77 \\
10 & Vale & Mineração & 73 \\
\hline
\end{tabular}

Fonte: Dados da pesquisa (2018)

Tabela 3: Classificação das Empresas com Maiores Níveis de Divulgação Voluntária Social

\begin{tabular}{cllc}
\hline Ordem & \multicolumn{1}{c}{ Empresa } & \multicolumn{1}{c}{ Setor/Segmento } & Divulgação (média/em \%) \\
\hline 61 & Ecorodovias & Transportes e Serviços & 29 \\
62 & B2W Digital & Comércio & 29 \\
63 & BR Pharma & Comércio & 29 \\
64 & Eletrobras & Energia Elétrica & 29 \\
65 & Minerva & Alimentos & 29 \\
66 & Dasa & Outros & 29 \\
67 & Magazine Luiza & Comércio & 27 \\
68 & Lojas Americanas & Comércio & 25 \\
69 & CESP & Energia Elétrica & 25 \\
70 & Multiplus & Outros & 25 \\
\hline
\end{tabular}

Fonte: Dados da pesquisa (2018)

A tabela 4 apresenta uma análise da divulgação social entre as empresas integrantes e não integrantes da carteira do Índice de Sustentabilidade Empresarial (ISE) da BM\&FBovespa no período de 2012. A média foi realizada utilizando isoladamente, apenas as empresas integrantes e não integrantes - obtendo o respectivo índice médio para aquelas empresas, e calculando da mesma forma a média para as 45 não integrantes.

Tabela 4: Análise da Divulgação Voluntária Social entre Empresas Integrantes as Não Integrantes da carteira do ISE

\begin{tabular}{cccc}
\hline Classificação & $\begin{array}{c}\text { Quantidade de } \\
\text { Empresas }\end{array}$ & $\begin{array}{c}\text { Representativo da } \\
\text { Amostra (em \%) }\end{array}$ & $\begin{array}{c}\text { Índice de Divulgação } \\
\text { média/em \%) }\end{array}$ \\
\hline Integrante & 25 & 36 & 56 \\
Não Integrante & 45 & 64 & 44 \\
\hline
\end{tabular}

Fonte: Dados da pesquisa (2018) 
Das 70 empresas da amostra, 25 participam da carteira ISE de 2012. Estas empresas, apesar de representarem um menor percentual da amostra deste estudo, possuem maior índice médio de divulgação do que as $64 \%$ empresas não integrantes do ISE. O ISE é uma instrumento que analisa o desempenho das empresas listadas na BM\&FBovespa quanto à sustentabilidade corporativa. Das organizações participantes de tal carteira, destacam-se as empresas pertencentes aos setores de Finanças e Seguros, em que este setor apresentou o quinto maior índice de divulgação voluntária dentre os demais.

Neste contexto, após a análise descritiva, foram realizadas as tabulações cruzadas e o teste Qui-quadrado entre as variáveis tamanho, rentabilidade, endividamento, participação no ISE, liquidez de mercado e o Índice de Divulgação Voluntária, ou IDV. A apresentação da análise cruzada entre a variável dependente com as independentes validadas segue a partir da tabela abaixo.

\subsection{Análise dos Resultados através da Tabulação Cruzada}

Tabela 5: Tamanho $x$ IDV

\begin{tabular}{cccc}
\hline Variável & \multicolumn{3}{c}{ Índice de Divulgação Voluntária } \\
\hline Ativo & Baixo & Amplo & Quantidade \\
Menor & 17 & 7 & 24 \\
Maior & 7 & 17 & 24 \\
\hline
\end{tabular}

Fonte: Dados da pesquisa (2018)

Percebe-se que das 24 empresas com menor valor de ativo, 71\% (ou 17), apresentam baixo índice de divulgação voluntária, enquanto que dentre as 24 maiores, apenas 7 empresas divulgam informações em nível mais baixo. Pode-se afirmar que, quanto maior o tamanho da empresa representado neste estudo pelo ativo total - mais ela evidencia e divulga informações voluntárias de caráter social. Este resultado corrobora com os estudos de Macagnan (2009) em que o tamanho da empresa explica a extensão da divulgação voluntária.

Tabela 6: Rentabilidade x IDV

\begin{tabular}{cccc}
\hline Variável & \multicolumn{3}{c}{ Índice de Divulgação Voluntária } \\
\hline ROE & Baixo & Amplo & Quantidade \\
Menor & 16 & 8 & 24 \\
Maior & 8 & 16 & 24 \\
\hline
\end{tabular}

Fonte: Dados da pesquisa (2018)

A rentabilidade é uma variável que influencia na divulgação da informação voluntária quanto mais rentável a organização, mais ela divulga. Por conseguinte, observa-se que, nos dados 
apresentados na Tabela 6, quanto maior o índice ROE - e com isso, mais ampla é a extensão da divulgação e quanto menor tal índice, menor é a divulgação. As 16 empresas mais rentáveis possuem uma divulgação mais ampla, enquanto que as 16 menos rentáveis evidenciam em menor escala suas informações.

Tabela 7: Liquidez de Mercado x IDV

\begin{tabular}{cccc}
\hline Variável & \multicolumn{3}{c}{ Índice de Divulgação Voluntária } \\
\hline LIQ & Baixo & Amplo & Quantidade \\
Menor & 16 & 8 & 24 \\
Maior & 8 & 16 & 24 \\
\hline
\end{tabular}

Fonte: Dados da pesquisa (2018)

A partir dos resultados acima, a liquidez de mercado apresenta relação com o IDV, confirmando a hipótese de que, quanto mais líquidas as ações das empresas, mais divulgam voluntariamente informações sobre as atividades sociais que realizam junto à comunidade. Percebese na Tabela 7 que das 24 empresas mais líquidas, 16 divulgam de forma mais ampla informações sociais voluntárias, confirmando a hipótese de pesquisa.

Tabela 8: Índice de Sustentabilidade Empresarial x IDV

\begin{tabular}{cccc}
\hline Variável & \multicolumn{3}{c}{ Índice de Divulgação Voluntária } \\
\hline ISE & Baixo & Amplo & Quantidade \\
Integrante & 8 & 17 & 25 \\
Não Integrante & 26 & 19 & 45 \\
\hline
\end{tabular}

Fonte: Dados da pesquisa (2018)

Percebe-se que, quando a empresa é participante da carteira do ISE, ela apresenta maior nível de divulgação voluntária de informação social - uma vez que das 25 empresas integrantes da carteira ISE em 2012, 17 possuem maior extensão de divulgação das informações, diferentemente, das empresas não participantes da carteira em que 58\% das não integrantes, não demonstram um maior nível de divulgação.

A hipótese é confirmada uma vez que, por ser integrante do ISE, a empresa apresenta maior índice de divulgação voluntária social, conforme Tabela 8.

\subsection{Análise dos Resultados por meio do Teste Qui-Quadrado}

O teste Qui-quadrado, realizado entre 48 empresas - ou seja, em 68,6\% da amostra deste trabalho, denota a existência de relação entre o Índice de Divulgação Voluntária e as variáveis 
tamanho, rentabilidade, liquidez de mercado e ISE apresentando tais variáveis significância estatística a níveis satisfatórios.

Vale ressaltar que o teste Qui-quadrado realizado com a variável ISE, foi utilizada a amostra das 70 (setenta) empresas do estudo. A partir dos dados, apenas a variável Endividamento, o teste não apresentou associação entre ela e a variável índice de divulgação voluntária, rejeitando a hipótese de que quanto maior o endividamento da empresa, maior o índice de divulgação de informações voluntárias sociais.

\section{Tabela 9: Teste Qui-Quadrado}

\begin{tabular}{lcc}
\hline \multicolumn{1}{c}{ Associações } & n & p-value \\
\hline Índice de Divulgação Voluntária x Tamanho & 48 & 0,000 \\
Índice de Divulgação Voluntária x Rentabilidade & 48 & 0,021 \\
Índice de Divulgação Voluntária x Endividamento & 48 & 0,193 \\
Índice de Divulgação Voluntária x Liquidez de Mercado & 48 & 0,021 \\
Índice de Divulgação Voluntária x ISE & 70 & 0,034 \\
\hline
\end{tabular}

Fonte: Dados da pesquisa (2018)

\section{Conclusão}

A divulgação de informações voluntárias realizada pelas empresas representa uma ferramenta para evidenciar os programas, projetos e atividades socialmente responsáveis realizadas pelas mesmas. Tem-se observado que devido à noção de responsabilidade corporativa - baseada na ideia de sustentabilidade - é crescente o volume de evidenciações corporativas de caráter voluntário, em que peculiarmente privilegiam questões de natureza social.

Baseado na teoria da divulgação voluntária e na teoria da legitimação, este estudo objetivou verificar a relação entre a divulgação voluntária de informações sociais e as determinadas características das empresas de capital aberto listadas na BM\&FBovespa, como o tamanho (ativo), o índice de rentabilidade, alavancagem, liquidez de mercado e participação na carteira ISE.

A amostra foi composta por 70 empresas, em que foram analisados os relatórios anuais e os relatórios de sustentabilidade no ano de 2012. Analisou-se o nível de divulgação voluntária de informações sociais evidenciadas nos respectivos relatórios, através de uma métrica que tornou possível a avaliação e mensuração do nível de divulgação voluntária social.

Em sua maioria, as empresas evidenciam possuir programas de voluntariado, apresentando de forma ampla os resultados sociais alcançados pelos projetos desenvolvidos, mas não as divulgam por projeto ou programa desenvolvido, assim como, não divulgam os programas sociais futuros, nem a projeção do fluxo de caixa dos mesmos, trazendo a conclusão de falta de comprometimento na continuidade, ou falta de interesse em desenvolver e especificar outros potenciais projetos. 
Dentre os principais resultados, destaca-se que o nível de divulgação voluntária analisado entre 48 empresas possui relação com o seu tamanho, liquidez de suas ações, rentabilidade e em estarem integrando o Índice de Sustentabilidade Empresarial. Além disso, o que leva as companhias a divulgarem informações sobre suas ações sociais está correlacionado à ideia de legitimidade e continuidade de suas operações - uma vez que maiores empresas, mais rentáveis, com maiores índices de negociabilidade e sustentáveis tendem a prestarem contas de projetos sociais desenvolvidos, objetivando permanecerem estrategicamente atuantes e responsáveis neste novo mercado socialmente responsável.

Assim, as principais contribuições deste estudo para a literatura contábil referente à divulgação de informações sociais residem na análise da informação voluntária social como a ampliação do escopo e suporte estratégico no planejamento da organização, influenciando na continuidade de suas operações e legitimação das mesmas, como também a constatação das características das empresas que estimulam a divulgação voluntária social.

Ressalta-se que os resultados aqui apresentados estão delimitados ao período e à amostra estudada e às variáveis utilizadas. Além disso, outros estudos poderão ser realizados levando em consideração proxies de retorno das ações, Níveis Diferenciados de Governança Corporativa e correlações relacionadas à participação das empresas em outros índices da BM\&FBovespa, bem como diferentes metodologias de construção da amostra.

\section{Referências}

BMF\&BOVESPA. Índice de Sustentabilidade Empresarial -ISE.2014. Disponível em: $<$ http://isebvmf.com.br/index.php?r=site/conteudo\&id=1>. Acesso em: 24 set. 2014.

BURGWAL, D.V. de; VIEIRA, Rui José O. Determinantes da divulgação ambiental em companhias abertas holandesas. Revista de Contabilidade e Finanças, São Paulo, v.25, nº 64, p. 60-78, jan./fev./mar./abr. 2014.

CUNHA, J.V.A.; RIBEIRO, M.S. Divulgação voluntária de informações de natureza social: um estudo nas empresas brasileiras. Revista de Administração Eletrônica, São Paulo, v.1, n.1, art.6, jan./jun. 2008.

DIAS FILHO, José Maria. Políticas de evidenciação contábil: um estudo de poder preditivo e explicativo da teoria da legitimidade.Anais...In: XXXI Encontro da ANPAD, 22., 2007. Rio de Janeiro.

GONÇALVES, Rodrigo de Souza. Social disclosure e Custo de Capital Próprio em empresas brasileiras de capital aberto. 2011. 165 f. Tese (Doutorado em Ciências Contábeis). Faculdade de Economia, Administração e Ciências Contábeis e Atuariais, Universidade de Brasília, Brasília, DF, 2011. Disponível em: 


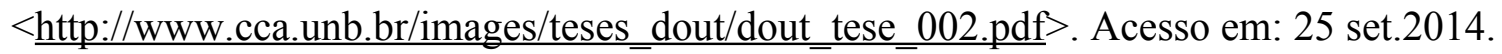

GONÇALVES, Rodrigo S,; MEDEIROS, Otávio R. de; NIYAMA, Jorge, K.; WELFORT, E.F.J.; Social disclosure e o custo de capital próprio em companhias abertas no Brasil. Revista Contabilidade \&Finanças, USP, São Paulo, v.24, n.62, p. 113-124, maio/jun./jul./ago. 2013.

GONÇALVES, Rosana C.M.G.; PIRANI, Diego C.; BORGER, Fernanda G. Qualidade das informações sobre responsabilidade social divulgadas pelos bancos privados com ações listadas no índice de sustentabilidade empresarial da Bovespa. Anais...In: XXXI Encontro da ANPAD, 22, 2007. Rio de Janeiro.

MACAGNAN, Clara Beatriz. Evidenciação voluntária: fatores explicativos da extensão da informação sobre recursos intangíveis. Revista Contabilidade \&Finanças, USP, São Paulo, v.20,n.50,p.46-61,maio/ago.2009.

MACHADO, Márcia Reis; MACHADO, Márcio A. V.; MURCIA, Fernando Dal R. Em busca da legitimidade social: relação entre o impacto ambiental da atividade econômica das empresas brasileiras e os investimentos no meio ambiente. Revista Universo Contábil, FURB, Blumenau, v.7, $n^{\circ} 1$, p. 20-35, jan/mar. 2011.

MAPURUNGA, P.V.R.; PONTE, V. M. R.; COELHO, A.C.D.; MENESES, A. F. de.; Determinantes do nível de disclosure de instrumentos financeiros derivativos em firmas brasileiras. Revista Contabilidade \& Finanças, São Paulo, v.22, n.57, p.263-278, set./nov./dez., 2011.

MILANI FILHO, M.A.F.Responsabilidade social e investimento social privado: entre o discurso e a evidenciação. Revista Contabilidade \& Finanças, USP, São Paulo, v. 19,n. 47, p. 89-101, maio/ago. 2008.

MORAES, Eliene Aparecida. Ambiente regulatório e evidenciação social: uma análise das empresas brasileiras listadas na BM\&FBovespa. 2014. $111 \mathrm{f}$. Dissertação (Mestrado em Ciências Contábeis). Faculdade de Economia, Administração e Ciências Contábeis e Atuariais, Universidade de Brasília, Brasília, DF, 2014.

MURCIA, Fernando Dal-Rio; SANTOS, Ariovaldo dos. Fatores determinantes do nível de disclosure voluntário das companhias abertas no Brasil. Revista Educação e Pesquisa em Contabilidade, v.3, $\mathrm{n}^{\mathrm{0}} 2$, p.72-95, mai./ago/set, 2009.

ROVER, Suliani. Disclosure Socioambiental e custo de capital próprio de companhias abertas no Brasil. 2013. 193 f. Tese (Doutorado em Ciências Contábeis) - Faculdade de Economia, Administração e Contabilidade, Universidade de São Paulo, São Paulo, 2013.

RUFINO, M.A.; MONTE, P.A. Fatores que explicam a divulgação de informações voluntárias das 100 empresas com ações mais negociadas na BM\&FBovespa. .In: VIII Congresso AnpCONT. Rio de Janeiro, 17 a 20 de agosto de 2014. Anais eletrônicos... Disponível $\mathrm{em}:<\underline{\mathrm{http}}: / / \mathrm{www}$.furb.br/ upl/files/especiais/anpcont/2014/239 3.pdf?20141017190056>. Acesso em: 10 out.2014.

SALOTTI, B.M.; YAMAMOTO, M.M. Ensaio sobre a teoria da divulgação. Brazilian Business Review, vol. 2, n. 1, jan,/jun., 2005, p. 53-70. 
TEIXEIRA, Evimael Alves; NOSSA, Valcemiro; FUNCHAL, Bruno. O índice de sustentabilidade empresarial (ISE) e os impactos no endividamento e na percepção de risco. Revista Contabilidade \& Finanças, São Paulo, v. 22, n. 55, p.29-44, 2011.

VELLANI, Cassio Luiz. Contabilidade e responsabilidade social: integrando desempenho econômico, social e ecológico. São Paulo: Atlas, 2011. 